\title{
Introduction to the Theme for 2016: Competencies, Milestones, and Entrustable Professional Activities
}

\author{
Peter G. M. de Jong ${ }^{1}$
}

Published online: 16 August 2016

(C) International Association of Medical Science Educators 2016

Last year, Medical Science Educator introduced "journal sections" on a specific topic. These thematic sections are the successor of the special issues that were published annually over the past several years. The content for the thematic sections is solicited by a special call for manuscripts, and for 2016, the accepted articles will be published in issues 26(3) and 26(4).

For the year 2016, the Editorial Board announced the topic of "Competencies, Milestones, and Entrustable Professional Activities." With this call, the journal wants to explore the way in which competencies and EPAs are being used in curricula in institutions around the world. I am very happy we received 25 submissions on this topic which have been peer-reviewed in our regular review process. The first 12 manuscripts are being presented in the current issue.

Over the years, competency-based education has become an important strategy in medical and nursing school curricula. It has become the basis for developing interprofessional education and practice. It should not surprise you that Medical Science Educator has also already published several studies on these topics in the last few years. Organizations like IAMSE and The Generalists in Medical Education have also paid attention to the topic in their annual conferences with lectures, sessions and workshops, [1].

In the special section of the current issue, we find not only a lot of experiences of schools with the concept of competencybased education and the use of milestones and EPAs but also some critical reflections on the true value of the competencybased approach. I am therefore convinced that you will enjoy these first 12 articles in this special journal section.

Peter G.M. de Jong, PhD

Editor-in-Chief

\section{References}

1. Outcomes, Competencies and Milestones across the Continuum The Generalists in Medical Education (TGME) 33rd Annual Meeting San Francisco, CA, USA, November 2-3, 2012. Med Sci Educ. 2013;23:67. doi:10.1007/BF03341806.
Peter G. M. de Jong

P.G.M.de_Jong@lumc.nl

Leiden University Medical Center, Leiden, The Netherlands 